\title{
Biological Invasion and Coexistence in Intraguild Predation
}

\author{
Wenting Wang, ${ }^{1}$ Xiaoli Feng, ${ }^{2}$ and Xiuping Chen ${ }^{1}$ \\ ${ }^{1}$ School of Mathematics and Computer Science, Northwest University for Nationalities, Lanzhou 730030, China \\ ${ }^{2}$ Department of Mathematics, Xidian University, Xian 710071, China \\ Correspondence should be addressed to Wenting Wang; sci-c-author@hotmail.com
}

Received 28 August 2012; Accepted 13 December 2012

Academic Editor: Julián López-Gómez

Copyright (C) 2013 Wenting Wang et al. This is an open access article distributed under the Creative Commons Attribution License, which permits unrestricted use, distribution, and reproduction in any medium, provided the original work is properly cited.

\begin{abstract}
Invasion of an exotic species initiated by its local introduction is considered subject to intraguild predation (IGP). Mathematically, the system dynamics is described by three nonlinear diffusion-reaction equations in two spatial dimensions. The key factors that determine successful invasion are investigated by means of extensive numerical simulations. The results reveal high asymmetry. An exotic species can invade successfully if it acted as the top predator and engaged in IGP, and the IGP interactions of the postinvasion web will be kept. While the exotic species were introduced as the intraguild prey (IGprey), they invade and spread through patchy invasion which corresponds to the invasion at the edge of extinction. Increase of the IGprey's dispersal rate and decrease of the IGpredator's may make the IGprey invade. But the interactions of the postinvasion web will change from IGP to competition, which is absolutely different from the first case. Finally, the common existence of IGP was explored once again from the perspective of biological invasion.
\end{abstract}

\section{Introduction}

Biological invasion is an issue of increasing importance in contemporary ecology and attracts considerable attention both from theoretical and field ecologists [1-5]. Among many issues related to biological invasions, the patterns and mechanisms of species spatial dispersal are of significant interest, while the interactions among factors determining invasion success often remain poorly understood [6]. Certainly, invasion success is influenced by the ability of invading individuals to withstand and overcome the various pressures of new host environments [7]. These include direct behavioral interactions with native species, such as competition and predation $[8,9]$. And it has been hypothesised previously that intraguild predation may be one of the key mechanisms of biological invasion [10-12].

Intraguild predation (IGP), when two species not only are engaged in a predator-prey relationship but also compete for a basic resource $[13,14]$, represents the simplest omnivorous type of species interaction. Theoretical studies suggested that the occurrence of omnivory destabilizes certain food chains as compared to linear food chain models $[13,15]$. Consequently, omnivory should be rare in nature if unstable food chains fail to persist. Additionally, based on the seminal theory developed by Holt and Polis [13] and subsequent extensions of this model [14,16-18], it is generally believed that coexistence of the intraguild predator (IGpredator) and the intraguild prey (IGprey) is only possible under very limited conditions, and only if the prey is more efficient in resource exploitation. These predictions corroborate with the previous opinions about the role of omnivory in food webs.

However, the empirical fact contrasts sharply with theoretical expectations. Intraguild predation is commonly found in many natural systems [19] and for a variety of different species such as insects, amphibians, and fish [20-22]. The food web of Broadstone Stream has been invaded by a new top predator, the nymph of the Golden-ringed Dragonfly, Cordulegaster boltonii Donovan (Anisoptera: Cordulegastridae). C. boltonii, which was extremely polyphagous and fed at all trophic levels, has invaded successfully and persistently proliferated. And the web complexity and omnivory also increased [11]. Recently two coccinellids with more catholic feeding habits, Coccinella septempunctata L. and Harmonia axyridis Pallas, have been introduced for aphid biocontrol and have become established throughout much of North America [23-27]. Both beetles feed not only on aphids, but also on a wide range of nonaphid preys including other predators [10, 28-31]. 
One major factor postulated to be important to the success of these two invaders is their tendency to engage in the intraguild predation (IGP) of native ladybirds [10, 12, 30-33].

There has been several reasons for the discrepancy. First, experiments are often too short for the system to reach a stable equilibrium, if there is equilibrium [34]. It is difficult to extrapolate short-term experiments to long-term effects of intraguild predation, especially when the populations exhibit fluctuations [35]. Second, theory is about well-mixed populations in an unstructured environment, whereas the spatial and temporal heterogeneity of nature has a profound effect on intraguild predation interaction [36, 37]. Moreover, dispersal enhances coexistence when a tradeoff between resource competition and IGP is strong or when the Intraguild Prey has an overall advantage [38]. Third, intraguild predation interactions are generally embedded in complex communities. For example, cannibalism promotes the coexistence of the IGpredator and IGprey [39], alternative prey can influence the persistence and stability of a local intraguild predation interaction [40]. All of above the reasons only explain the stabilities and coexistence of postinvasion web, while there are few theoretical studies on whether and how an exotic species could invade the preinvasion web successfully through prevalent intraguild predation. In this study, an exotic species was introduced and the coexistence of invader and natives was explored through intraguild predation.

The combination of biological invasion and IGP in our study was particularly fortuitous, for two reasons. First, although a number of factors contribute to an exotic species being a successful invader, including release from natural enemies and parasites [41], and ecological disturbance by humans that opens colonization sites [42], most introduced species fail to invade successfully [42], and ecologists remain limited in their ability to identify likely successful invaders before the fact. Recently, several authors have suggested that IGP of natives by exotics is likely contributing to the invasion $[8,32,43,44]$. Second, biological invasions provide opportunities to study how food webs develop and have been modeled extensively (e.g., $[45,46])$, although empirical data are scarce. Therefore, we also expected to explain the common existence of IGP from the perspective of biological invasion.

Partial differential equations (PDEs) provide a means of melding organism movement with population processes and have been used extensively to elucidate the effects of spatial variation on populations. In this paper, PDEs were used to model the phenomena of biological invasion, and the IGP model of reaction-diffusion type was set up. First, the local reactive kinetic of IGP (i.e., the IGP system without diffusion) was explored and the alternative equilibria were considered, which are (1) only the resource and the IGprey are present, the IGpredator cannot invade; (2) only the resource and IGpredator are present, the IGprey cannot invade. Second, with the spatial factors and species dispersal considered, the exotic species were introduced as IGprey and IGpredator, respectively. And the mechanisms of biological invasion and coexistence were studied. The influence of dispersal rate on the population abundance of IGP interaction will also be investigated.

\section{Model and Method}

To examine the exotic invasion and coexistence with native via IGP, we consider the two-dimensional spatial dynamics of a IGP system described by three partial differential equations of reaction-diffusion type. This system is considered in a homogeneous environment and is a simple extension of diffusive predator-prey model $[3,47,48]$.

Let $R, N$, and $P$ denote the abundance of basic resource, IGprey and IGpredator, respectively. we assume that in the absence of predators, the basal resource grows logistically, with maximum intrinsic growth rate, $r$, and carrying capacity, $K$. The IGprey feeds on the basal resource with attack rate $a_{R N}$, converting consumed resource into new predators with conversion efficiency, $c_{R N}$. The functional response of IGprey is Holling type I. The IGpredator can feed on both the basal resource (with attack rate $a_{R P}$ and conversion efficiency $c_{R P}$, Holling type I functional responses) and the IGprey (with attack rate $a_{N P}$ and conversion efficiency $c_{N P}$, Holling type II functional responses). We assume that predators $N$ and $P$ have density-independent per capita death rates, $E_{N}$ and $E_{P}$, respectively. With these assumptions, the spatiotemporal dynamics of IGP are described by the following:

$$
\begin{aligned}
& \frac{\partial R(r, T)}{\partial T}=D_{1} \nabla^{2} R(r, T)+r R\left(1-\frac{R}{K}\right)-a_{R N} R N-a_{R P} R P, \\
& \frac{\partial N(r, T)}{\partial T}=D_{2} \nabla^{2} N(r, T)+c_{R N} a_{R N} R N-\frac{a_{N P} N P}{N+H}-E_{N} N,
\end{aligned}
$$

$$
\frac{\partial P(r, T)}{\partial T}=D_{3} \nabla^{2} P(r, T)+c_{R P} a_{R P} R P+\frac{c_{N P} a_{N P} N P}{N+H}-E_{P} P
$$

where $r=(X, Y)$ is the location in space. $T$ is time. $D_{i}(i=$ $1,2,3)$ is the diffusion coefficient that measures dispersal rate, with units distance ${ }^{2} /$ time. And $H$ is the half-saturation IGprey density.

In order to reduce the number of model parameters we introduce dimensionless variables: $u=R / K, v=$ $a_{R N} N /\left(c_{R N} a_{R N} K\right), w=a_{R P} P /\left(c_{R P} a_{R P} K\right), t=r T, x=X(r /$ $\left.D_{1}\right)^{1 / 2}, y=Y\left(r / D_{1}\right)^{1 / 2}$.

Then, (1a)-(1c) can be rewritten as the following:

$$
\begin{gathered}
\frac{\partial u}{\partial t}=\nabla^{2} u+u(1-u)-\kappa_{1} u v-\kappa_{2} u w \\
\frac{\partial v}{\partial t}=\varepsilon_{1} \nabla^{2} v+\kappa_{1} u v-\frac{\alpha \kappa_{3} v w}{v+h}-e_{1} v \\
\frac{\partial w}{\partial t}=\varepsilon_{2} \nabla^{2} w+\kappa_{2} u w+\frac{\kappa_{3} v w}{v+h}-e_{2} w
\end{gathered}
$$

where $\kappa_{1}=c_{R N} a_{R N} K / r, \kappa_{2}=c_{R P} a_{R P} K / r, \kappa_{3}=c_{R P} a_{R P} / r$, $4 \alpha=1 / c_{R N}, h=H / c_{R N} K, e_{1}=E_{N} / r, e_{2}=E_{P} / r, \varepsilon_{1}=D_{2} /$ $D_{1}$, and $\varepsilon_{2}=D_{3} / D_{1}$. 


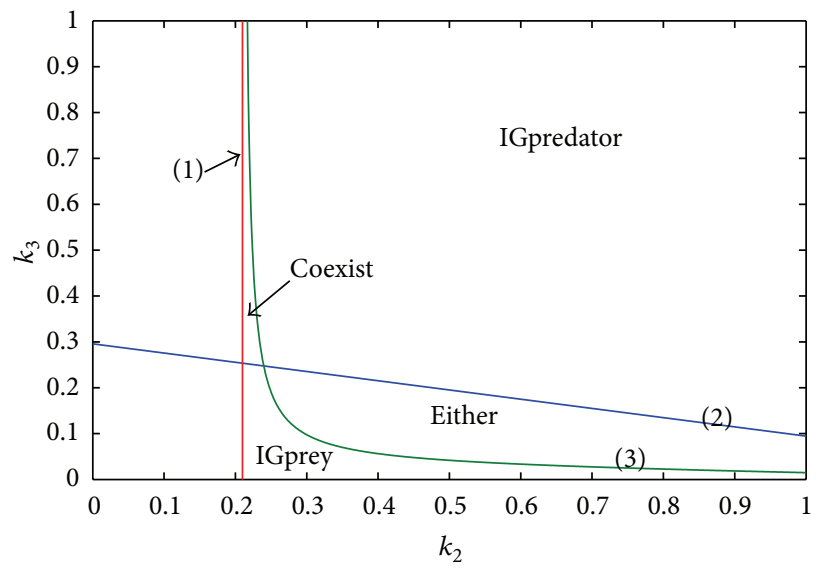

FIGURE 1: Regions of potential coexistence for the local reactive kinetic of (2a)-(2c). In the region labeled "IGprey" (on the right side of the line marked "(1)" and below the line marked "(3)"), the IGprey extirpates the IGpredator, whereas in the region labeled "IGpredator" (in the right of the line marked "(1)" and above the line marked "(2)"), the IGpredator extirpates the IGprey. Region labeled "either" is that in which coexistence is not possible, but the species that persists depends on initial conditions. Region labeled "Coexist" is the intersection of the regions labeled "IGprey" and "IGpredator." Parameter values were chosen to be system appropriate: $\kappa_{1}=0.7, \alpha=2, h=0.5, e_{1}=0.1$, and $e_{2}=0.21$.

To understand well the dynamics of the system given by (2a)-(2c), it is worth giving a brief account of the properties of the well-mixed, spatially homogeneous system without diffusion terms (i.e., local reactive kinetics). The system has five possible equilibria: (i) total extinction $(0,0,0)$; (ii) Only the resource is presence $(1,0,0)$; (iii) the resource and IGprey are presence $\left(e_{1} / \kappa_{1},\left(1 / \kappa_{1}\right)\left(1-e_{1} / \kappa_{1}\right), 0\right)$; (iv) the resource and IGpredator are presence $\left(e_{2} / \kappa_{2}, 0,\left(1 / \kappa_{2}\right)\left(1-e_{2} / \kappa_{2}\right)\right) ;(\mathrm{v})$ all species are present $\left(u^{*}, v^{*}, w^{*}\right)$; (see the Appendix for infomations about the equilibria).

Using invasion analysis [13,49], we can obtain the following: (1) the predator can invade when rare (i.e., its per capita growth rate at low density is positive) if $\kappa_{2} e_{1} / \kappa_{1}+\kappa_{3}\left(\kappa_{1}-\right.$ $\left.e_{1}\right) /\left(\kappa_{1}-e_{1}+h \kappa_{1}^{2}\right)-e_{2}>0$; (2) the prey can invade when rare if $\kappa_{1} e_{2} / \kappa_{2}-\alpha \kappa_{3}\left(\kappa_{2}-e_{2}\right) / \kappa_{2}^{2} h-e_{1}>0$. When the invasion criteria are both satisfied, the prey and the predator can coexist.

Because the goal is to explore whether IGP interaction has a positive effect on the invasion of exotic organism and revisit the coexistence of IGP from the perspective of biological invasion, we restrict attention to the following two situations: (1) only the resource and IGprey are present; (2) only the resource and IGpredator are present. Rather than attempting an exhaustive exploration of the parameter space we only choose two sets of parameters that represent above situations, respectively.

The system (2a)-(2c) was solved numerically by finite differences. Computer experiments were run in a square numerical domain $L \times L$ where $L=300$. And the explicit scheme was used. Also sensitivity of the results with respect to the values of the grid steps was checked and they were chosen reasonably small to avoid any essential numerical artifact. At the boundary of the domain, the zero-flux boundary conditions were used.

\section{Simulation Analysis and Results}

For the local reactive kinetic of the IGP model (2a)-(2c), coexistence of the two consumers on the single resource is possible only if the IGprey is more efficient than the IGpredator at suppressing the abundance of the basal resource, and if the IGpredator accrues a sufficient gain from attacking the IGprey. Figure 1 shows the equilibrium invasion criteria for the local reactive kinetics of model $(2 \mathrm{a})-(2 \mathrm{c})$. Coexistence of the two consumers is possible (but not ensured) if invasion by each species into an equilibrium of its competitor is possible (i.e., $\kappa_{1}>e_{1}$ and $\kappa_{2}>e_{2}$ ). Mutual invisibility may not lead to stable coexistence; numerical analysis suggests that the equilibrium is largely influenced by the intensity of omnivorous $\left(\kappa_{3}\right)$.

Biological invasion usually starts with a local introduction of exotic species; thus, relevant initial conditions for system (2a)-(2c) should be described by functions of compact support when the density of one or both species at the initial moment of time is nonzero only inside a certain domain. The shape of the domain and the profiles of the population densities can be different in different cases [50]. In order to study the effect of IGP on the biological invasion in model (2a)-(2c), we firstly choose the parameters from Figure 1 in which the IGpredator cannot invade and the initial distribution of species was taken as follows: $u(r, 0)=$ 0.2 , if $50<x<130$ and $110<y<190$ or if $140<x<240$ and $60<y<160$, otherwise, $u(r, 0)=0 ; v(r, 0)=0.7$, if $150<x<230$ and $70<y<150$, otherwise, $v(r, 0)=0$; $w(r, 0)=0.5$, if $60<x<120$ and $120<y<180$ or if $160<$ $x<220$ and $80<y<140$, otherwise, $w(r, 0)=0$. Results of our computer simulations show that, the alien species can invade and propagate via continuous travelling population 


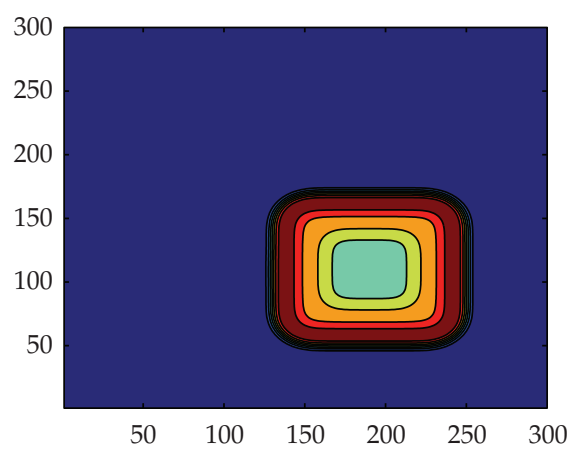

(a)

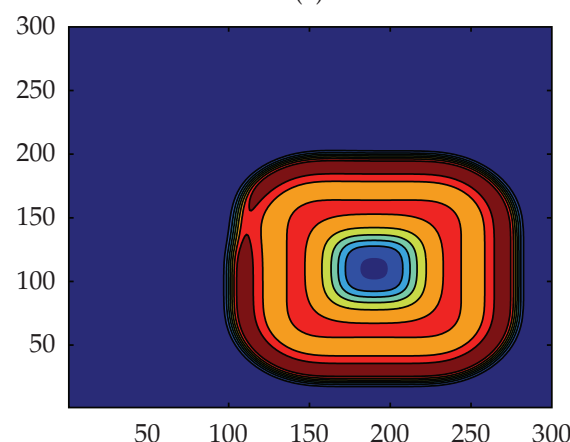

(b)

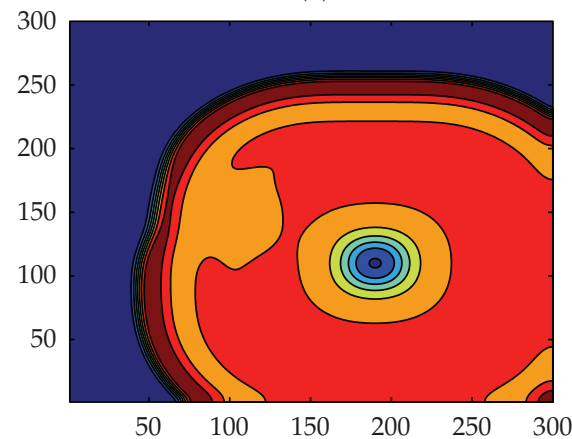

(c)

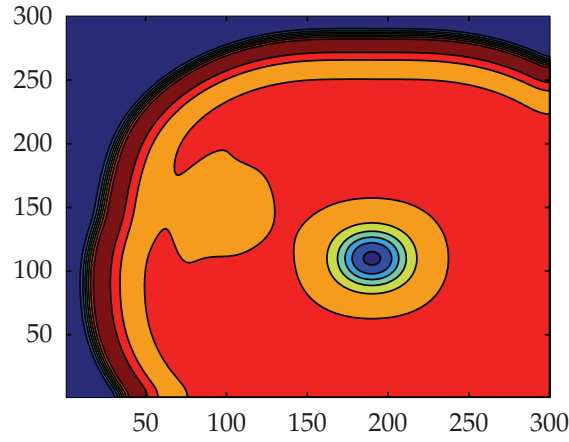

(d)

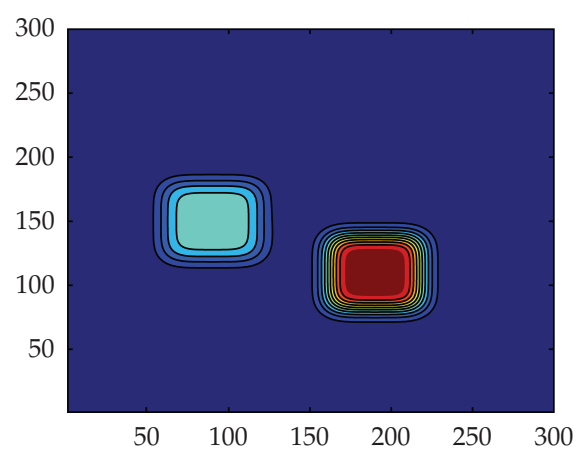

$\left(a^{\prime}\right)$
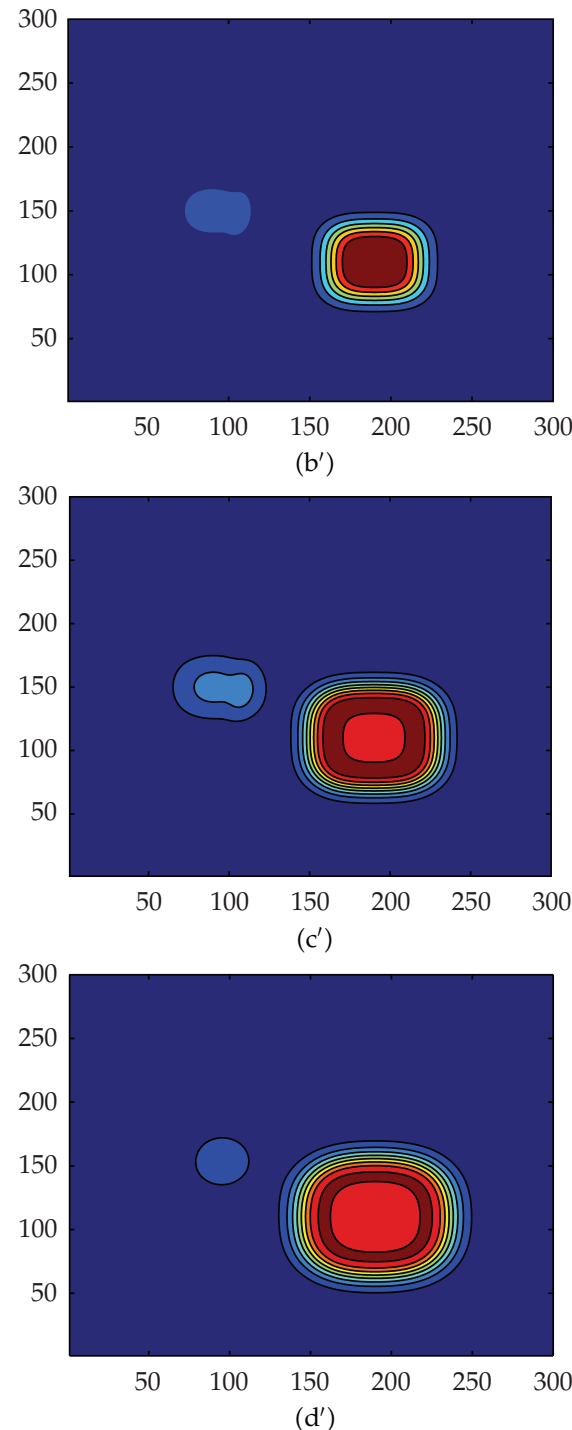

FIGURE 2: Typical spatial pattern of the density of IGprey (left column) and IGpredator (right column) in two-dimensional space for the system (2a)-(2c). Parameter values: $\kappa_{1}=0.7, \kappa_{2}=0.2, \kappa_{3}=0.23, \alpha=2, h=0.5, e_{1}=0.1, e_{2}=0.21, \varepsilon_{1}=1$, and $\varepsilon_{2}=1.5$. From the top row to bottom, panel represents spatial patterns at time $100,300,600$, and 1,000 , respectively.

fronts if they feed on resources at different trophic levels (i.e., IGP), whereas it is hard to survive when they were introduced to the place where only the basal resource exists (Figures $\left.2\left(a^{\prime}\right)-2\left(d^{\prime}\right)\right)$. When the IGpredator invades successfully and coexists with the others, the IGprey's abundance declines at first and then increases, but the resource's is the opposite (Figure 3).

The long-term abundances of the resource, the IGprey and the IGpredator, are affected by the IGprey's dispersal rate $\left(\varepsilon_{1}\right)$ and the IGpredator's dispersal rate $\left(\varepsilon_{2}\right)$ (Figure 4 ). More 


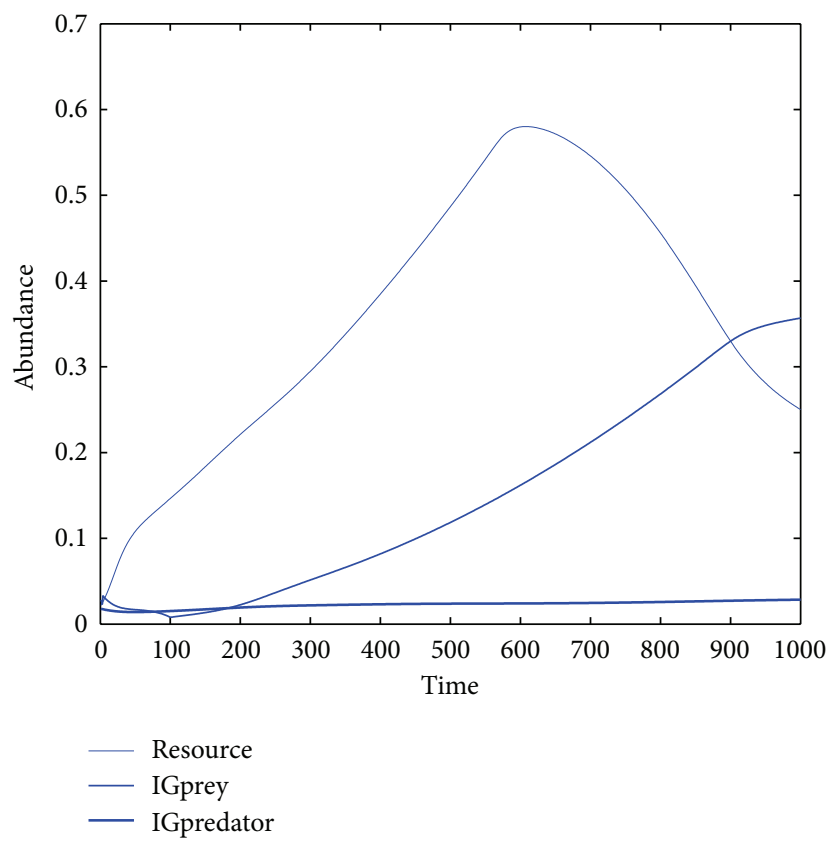

FIGURE 3: The population dynamics of the IGP system with diffusion. All parameter values are the same as Figure 2.

precisely, the abundances of the IGprey and the resource are only affected by the IGpredator's dispersal rate, while the abundance of the IGpredator is affected by the dispersal rate of the both. When the IGpredator's dispersal rate increases, the abundances of the IGpredator and the IGprey increases and the resource's decreases (Figures 4(a) and 4(b)). When the IGpredator's dispersal rate is very small, its abundance increases initially and then decreases with increasing the IGprey's dispersal rate. While the IGpredator's dispersal rate is large, its abundance decreases monotonically (Figure 4(c)).

Next, we chose the parameters from Figure 1 on which the IGprey cannot invade and the initial distribution of species was taken as follows: $u(r, 0)=0.5$, if $100<x<200$ and $100<y<200$, otherwise, $u(r, 0)=0 ; v(r, 0)=0.8$, if $110<x<190$ and $110<y<190$, otherwise, $v(r, 0)=0$; $w(r, 0)=0.5$, if $120<x<180$ and $120<y<180$, otherwise, $w(r, 0)=0$. The IGprey invades and yields a completely different pattern of population spread, in particular, the regime of patchy invasion $[51,52]$, which is shown in Figure 5 as an example. At the early stage of the system dynamics, the species spread is characterized by formation of a continuous front (see Figure 5(a)). At later time, however, the front breaks into pieces and no continuous front arises again, (cf. Figures 5(c) and 5(d)). Apparently, a structure of niche partition arises (Figures 5(b)-5(d)). When the IGprey is introduced to this system, the abundance of the resource and the IGpredator gradually increase initially, but the increasing trend of resource is stronger than the IGpredator's. During a period of time, the IGpredator still keeps monotonically increasing, and the abundance of IGprey forms a hump, but the resource sharply decreases after reaching the maximum value (Figure 6).
The abundances of the resource and the IGprey are not influenced by certain parameters regions, which are characterized by relatively small dispersal rate of IGprey and the corresponding dispersal rate of IGpredator determined by the variation of IGprey's dispersal rate. Except the above extreme case, the abundance of the resource decreases with increase of IGprey's dispersal rate and decrease of IGpredator's dispersal rate, however, the IGprey is contrary to it (Figures 7(a) and 7(b)). The abundance of the IGpredator increases with dispersal rate of both IGprey and IGpredator increasing, especially, there arises a steep slope in the variable process (Figure 7(c)).

\section{Discussion}

Since Elton's classic treatise [53], there has been great interest in the conditions that make habitats invisible [54], in the life histories and genetics of invaders [55], and in the ecological impact of invasions [54]. Ecologists have long sought to identify key factors that determine why some exotic species turn invasive and damaging to native species while others fail to do so (e.g., [56]). Successful invasion involves a number of stages, including initial introduction; establishment in the new habitat; and range expansion. Amongst biological control practitioners, these topics have recently become of great interest in regards to the establishment and spread of introduced aphidophagous ladybirds (Coleoptera: Coccinellidae). Two ladybird species in particular have been spectacular in their success as invaders in North America: Coccinella septempunctata Linn. (e.g., [26, 57-59]) and Harmonia axyridis Pallas (e.g., $[24,27,60,61])$. Harmonia axyridis and C. septempunctata are native to Japan, where they often dominate ladybird guilds (e.g., [62]). Recently, 


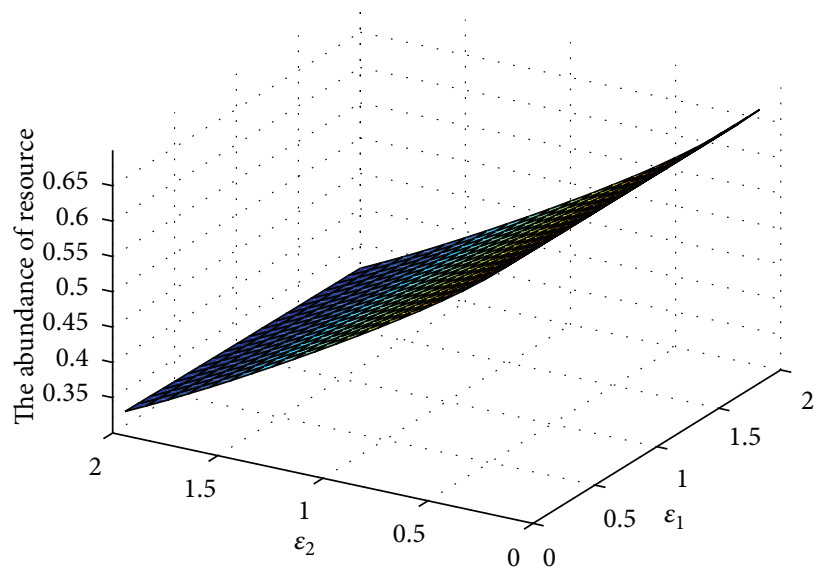

(a)

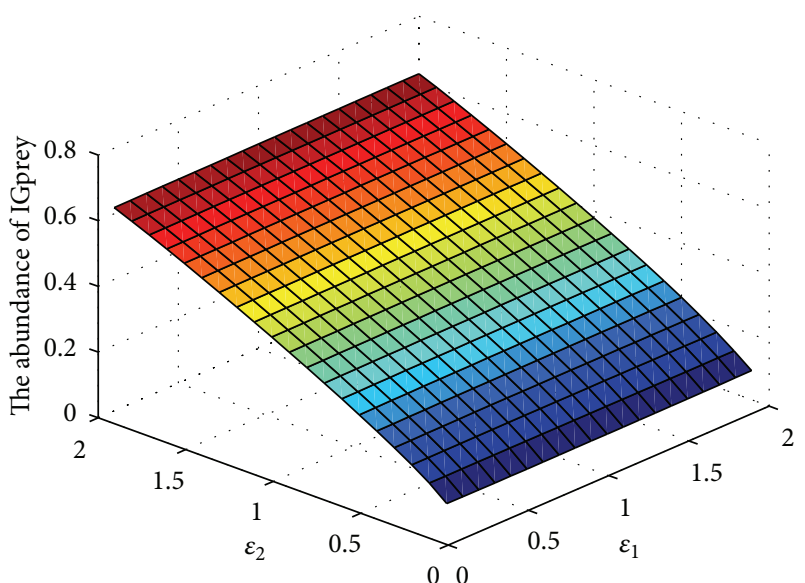

(b)

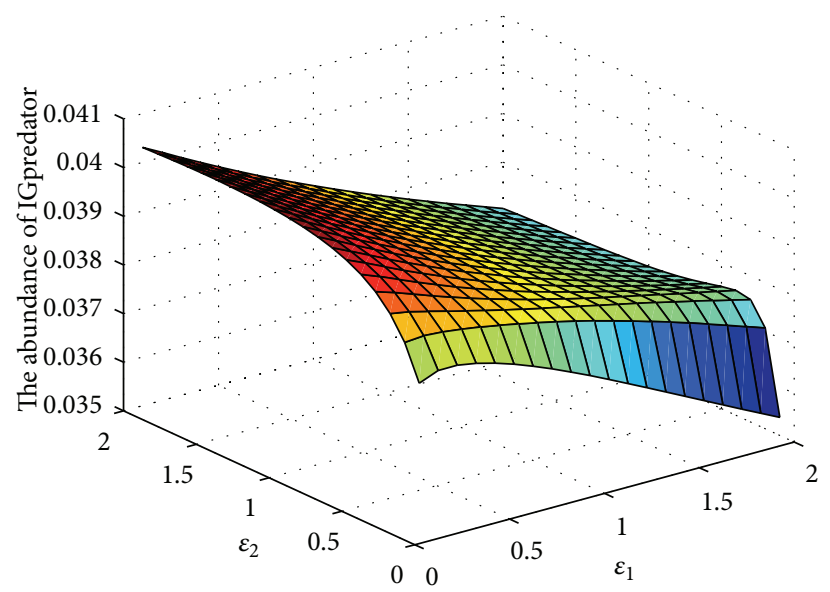

(c)

FIGURE 4: Long-term (equilibrium) abundances of the resource, the IGprey and the IGpredator as a function of the IGprey's dispersal rate $\left(\varepsilon_{1}\right)$ and the IGpredator's dispersal rate $\left(\varepsilon_{2}\right)$. Parameter values used are: $\kappa_{1}=0.7, \kappa_{2}=0.2, \kappa_{3}=0.23, \alpha=2, h=0.5, e_{1}=0.1$, and $e_{2}=0.21$.

the two-spotted ladybird, Adalia bipunctata (Linn.), an exotic to Japan, was introduced at the port town of Osaka [63], but it did not succeed in expanding its distribution [64]. The all above facts told us that successful invasion relates to direct or indirect trophic level relationships with natives. However, few studies have investigated the mechanisms of biological invasion and coexistence in a natural community with IGP. In this paper, a theoretical investigation was conducted to study the effect of IGP on biological invasion and coexistence through constructing PDEs models. Moreover, the common coexistence of IGP will also be explained from the perspective of biological invasion.

Through the analysis of the local reactive kinetics of model (2a)-(2c), we mainly focused on two situations: (1) only the resource and the IGprey are present, the IGpredator cannot invade, and (2) only the resource and IGpredator are present, the IGprey cannot invade. We found, when the exotic species was introduced to the first situation and acted as the IGpredator, that they can invade successfully and propagate via continuous travelling population fronts, whereas it is hard to survive when they were introduced to the place where only the basal resource exists (Figures $2\left(\mathrm{a}^{\prime}\right)-2\left(\mathrm{~d}^{\prime}\right)$ ). This result supported the hypothesis that the success of Harmonia axyridis and C. septempunctata is their tendency to engage in the intraguild predation (IGP) of native ladybirds $[10,12,30$ 33].

However, when the exotic species were introduced to the second situation and acted as the IGprey, they invade and spread through patchy invasion (Figure 4). The patchy spread corresponds to the invasion at the edge of extinction so that a small variation of parameters either restores the usual scenario of invasion via travelling population waves or brings the species to extinction [65]. For example, with decrease of the IGprey's dispersal rate, the exotic species will extinct at last (Figure 7(b)). Our result concludes that IGP by native species is one of the key mechanisms of biotic resistance responsible for the failure of an exotic species to invade. This result can explain why A. bipunctata did not establish in Japan. Elton [53] also suggested that many species are invasive because they arrive in areas without their natural 

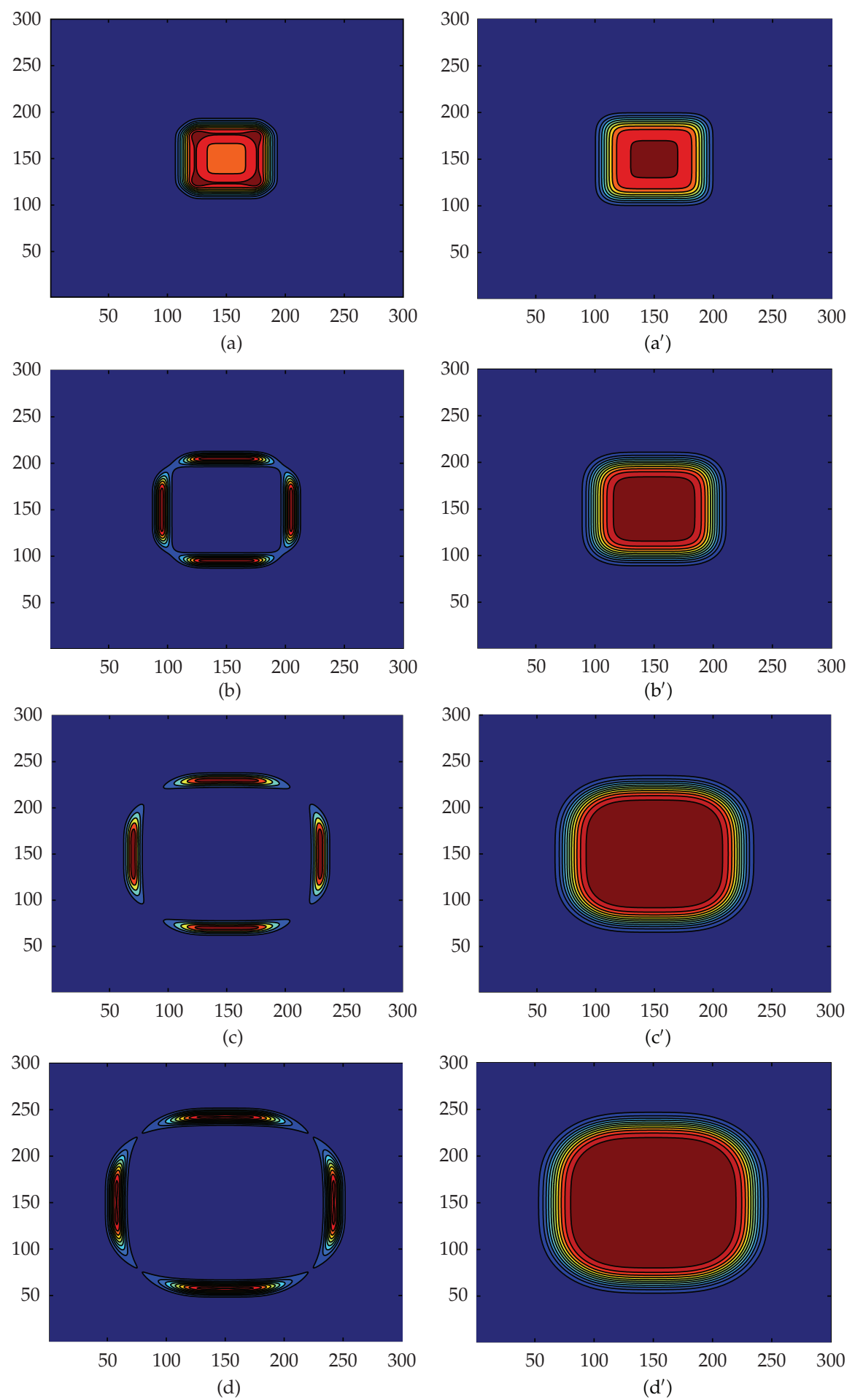

FIGURE 5: Typical spatial pattern of the density of IGprey (left column) and IGpredator (right column) in two-dimensional space for the system (2a)-(2c). Parameter values: $\kappa_{1}=0.7, \kappa_{2}=0.4, \kappa_{3}=0.4, \alpha=2, h=0.5, e_{1}=0.1, e_{2}=0.21, \varepsilon_{1}=1.5$, and $\varepsilon_{2}=2$. From the top row to bottom, panel represents spatial patterns at time $100,300,600$, and 1,000, respectively.

enemies [53]. A new top predator, the dragonfly Cordulegaster boltonii Donovan, has invaded and persistently proliferated within the food web of Broadstone Stream over the past 25 years; no other species have invaded successfully at the lower trophic levels [11]. Therefore, the successful invasion is more easily achieved by an exotic species which engages in the IGP of native species.

The establishment of the IGpredator may bring the decline in IGprey at the beginning and the increase later, but the resource's is the opposite (Figure 3). The biological 


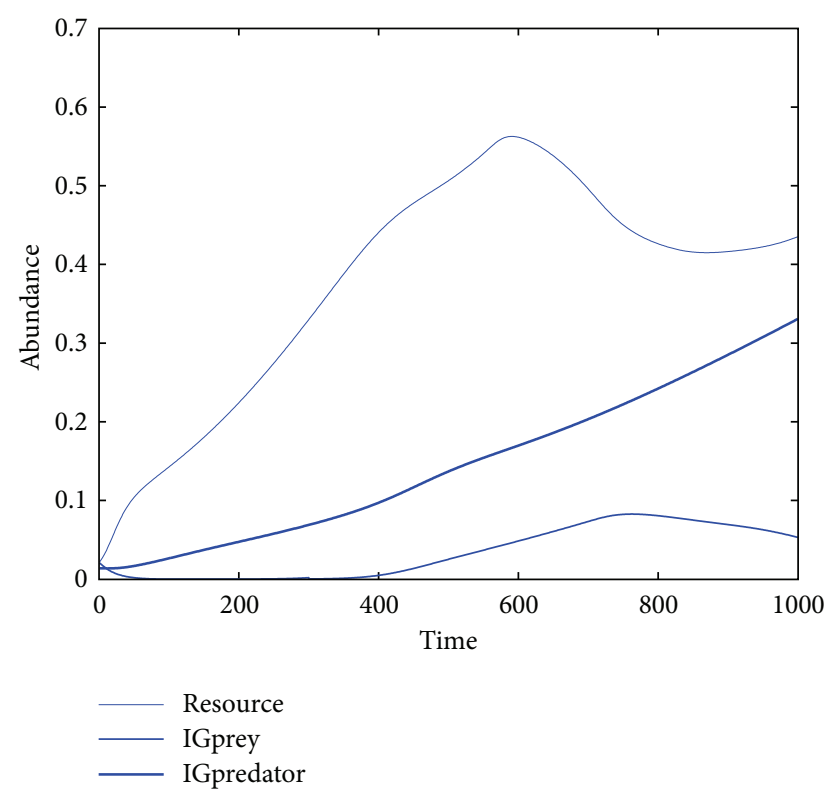

FIGURE 6: The population dynamics of the IGP system with diffusion. All parameter values are the same as Figure 5.

reasons could be as follows. Because the IGpredator interacts indirectly by competing for shared resources and directly through intraguild predation, the IGprey will face the double pressure of resource competition and predation risk thus naturally decrease at the early stage. As the IGprey declines, the resource will increase, although the IGpredator also feeds on it. This "trophic cascades" occurrence may be the weak link between the IGpredator and resource (e.g., $\kappa_{3}=0.2$ ). Spatial dispersal also has an influence on the coexistence of IGP. The IGprey can escape from the hunting of IGpredator through dispersal and gradually increase. Certainly, the resource will decrease as a result of been consumed.

Because the IGprey invades at the edge of extinction (Figure 5) and has a extinction risk for a long time (Figure 6), the abundance of the resource and the IGprey are not essentially affected by the invasion of IGprey and increase at the initial stage. Escaping from the hunting of IGpredator, the IGprey spread at the periphery of the IGpredator. That is to say, the IGprey and IGpredator suffer from the niche partition (Figures 5(b)-5(d)), the relationship of which is not IGP any longer but competition. Without the predation risk, the IGprey increases. As the result of competition of two preys for the resource, the abundance of resource declines. Because of reduction in the resource, the IGprey decreases after reaching the maximum abundance (Figure 6).

After studying the mechanisms of biological invasion through IGP, it is necessary to consider the coexistence of postinvasion web. We found the asymmetric dispersal of IGP has an important effect on the coexistence and abundance of species. First, the spatial dispersal enhances invasion and coexistence when an exotic species cannot invade and coexist with the natives in the local reaction kinetic system. As shown in Amarasekare's study [38], random dispersal enhances coexistence when a tradeoff between resource competition and IGP is strong and/or when the IGPrey has an overall advantage. The simulation result in our study showed that this conclusion also seemed to be true for the IGP system of reaction-diffusion type.

Second, dispersal plays a different role in species coexistence when an asymmetric invasion occurs via IGP. When an exotic species was introduced to engage in IGP, both the alien and natives coexist and keep the relationship of IGP. Dispersal only has an influence on the abundance of the coexisting species. Because of low-density invasion of the IGpredator, its abundance is sensitive to the IGprey's dispersal. The IGprey escapes from being hunted through dispersal, thus the IGpredator will decline as a result of the lack of food (Figure 4(c)). With increase of the IGpredator's dispersal, its opportunities for predation augment and then its abundance also increase. Analogous to the paradox of enrichment [66], the IGprey increases with the increase of IGpredator (Figure 4(b)). The biological reason for this phenomena could due to the low-density invasion of the IGpredator and the enrichment of the resource. It is clear that the resource is rapidly consumed with the increase of IGpredator's dispersal (Figure 4(a)). When an exotic species invades as the IGprey, there are two results: coexistence or not. Increasing the IGprey's dispersal rate and decreasing the IGpredator's may enhance coexistence (Figures 7(a) and $7(b))$. However, the interactions change from IGP to competition and the IGprey survives from niche partition.

Biological invasions are a worldwide phenomenon that threatens to dramatically change the interactions of preinvasion web. When an exotic species invades as the top predator, it can take two strategies: only feeds on the resource and feeds on both native predator and resource. Simulation results show that successful invasion occurs by means of the second strategy (Figure 2). That is to say, IGP is an optimal strategy in biological invasion, thus it can be favored by the 


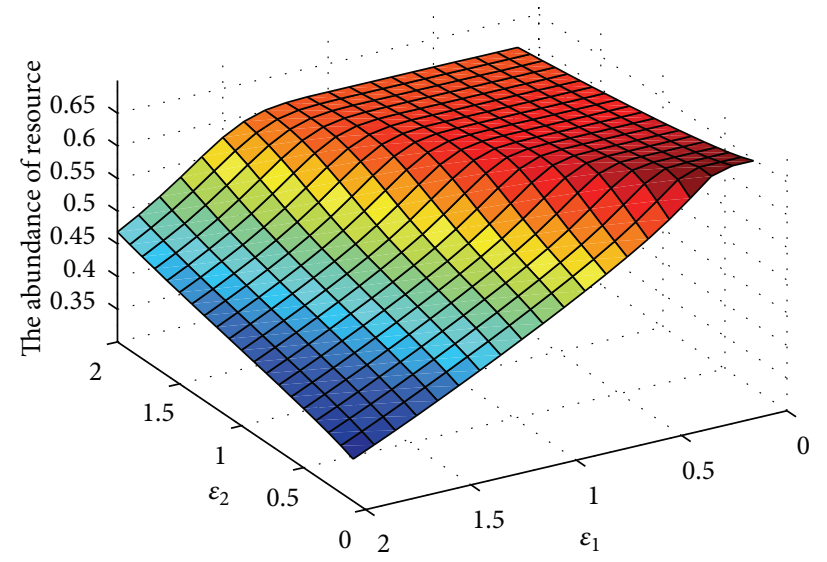

(a)

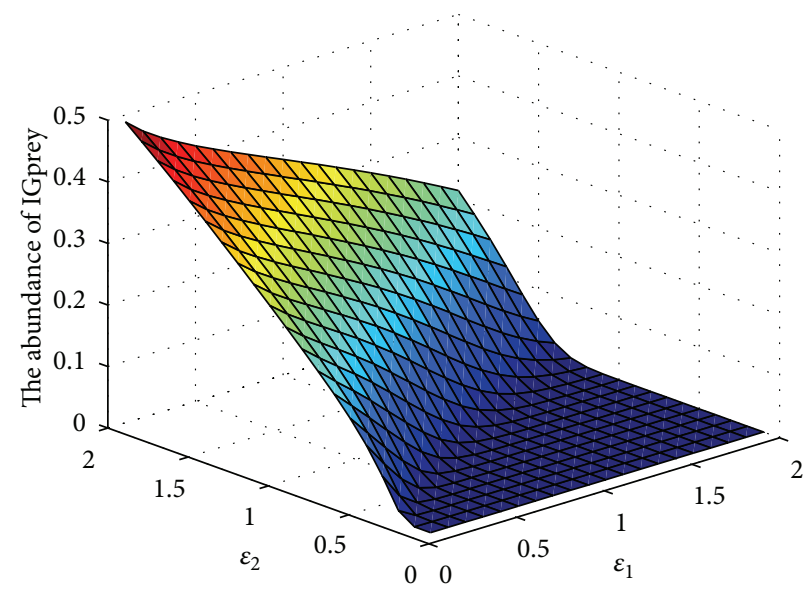

(b)

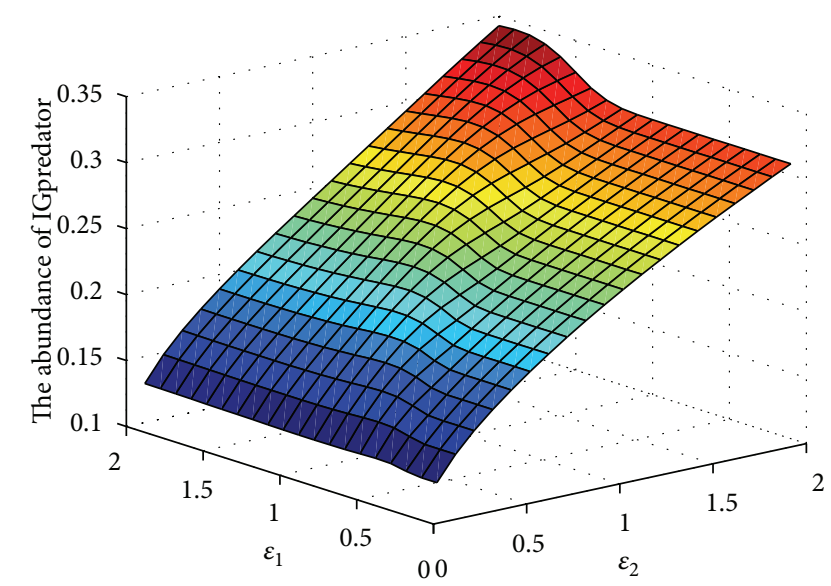

(c)

FIGURE 7: Long-term (equilibrium) abundances of the resource, the IGprey and the IGpredator as a function of the IGprey's dispersal rate $\left(\varepsilon_{1}\right)$ and the IGpredator's dispersal rate $\left(\varepsilon_{2}\right)$. Parameter values used are $\kappa_{1}=0.7, \kappa_{2}=0.4, \kappa_{3}=0.4, \alpha=2, h=0.5, e_{1}=0.1$, and $e_{2}=0.21$.

natural selection. Therefore, the interaction of pre-invasion web will be changed to IGP. From the standpoint of biological invasion, IGP is commonly found in nature. This issue is the first study that theoretically demonstrates the effect of IGP on biological invasion and coexistence and also is an innovation that explains why IGP commonly exists in nature from the perspective of biological invasion.

\section{Appendix}

The properties of the well-mixed, spatially homogeneous system, that is, (2a)-(2c) without diffusion terms, is written as follows:

$$
\begin{gathered}
\frac{d u}{d t}=u\left[(1-u)-\kappa_{1} v-\kappa_{2} w\right], \\
\frac{d v}{d t}=v\left[\kappa_{1} u-\frac{\alpha \kappa_{3} w}{v+h}-e_{1}\right],
\end{gathered}
$$

$$
\frac{d w}{d t}=w\left[\kappa_{2} u+\frac{\kappa_{3} v}{v+h}-e_{2}\right]
$$

The system has five possible equilibria: (i) total extinction $(0,0,0)$; (ii) only the resource is presence $(1,0,0)$; (iii) the resource and IGprey are presence $\left(e_{1} / \kappa_{1},\left(1 / \kappa_{1}\right)(1-\right.$ $\left.e_{1} / \kappa_{1}\right), 0$ ); (iv) the resource and IGpredator are presence $\left(e_{2} / \kappa_{2}, 0,\left(1 / \kappa_{2}\right)\left(1-e_{2} / \kappa_{2}\right)\right) ;(\mathrm{v})$ all species are present $\left(u^{*}, v^{*}, w^{*}\right)$, where

$$
\begin{gathered}
u^{*}=1-\kappa_{1} * v^{*}-\kappa_{2} * w^{*}, \\
v^{*}=\frac{-B+\sqrt{\Delta}}{2 D}, \\
w^{*}=\frac{1}{\kappa_{2}}\left(-\kappa_{1} v^{*}+\frac{1}{\kappa_{2}} \frac{\kappa_{3} v^{*}}{v^{*}+h}-\frac{e_{2}}{\kappa_{2}}\right),
\end{gathered}
$$


where

$$
\begin{gathered}
D=\kappa_{1} \kappa_{2}\left(\kappa_{2}-e_{2}\right)-(1-\alpha) \kappa_{1} \kappa_{2} \kappa_{3}-e_{1} h^{2}, \\
B=2 h \kappa_{1} \kappa_{2}\left(\kappa_{2}+e_{2}\right)-2 e_{1} h^{3}+\kappa_{1} \kappa_{2} \kappa_{3} h(\alpha-1) \\
\quad-\alpha \kappa_{1} \kappa_{3}^{2}+\alpha \kappa_{3} e_{2}, \\
\Delta=B^{2}-4 D\left[\left(\kappa_{1} \kappa_{2}^{2}+\kappa_{1} \kappa_{2} e_{2}-e_{1} h^{2}\right) h^{2}+\alpha \kappa_{3} e_{2} h\right] .
\end{gathered}
$$

System (A.1a)-(A.1c) is too complicated to evaluate the local stability through standard procedures. Here, we will analyze the equilibria stabilities by invasion analysis [13, 49].

Obviously, equilibrium (i) is unstable because of a positive carrying capacity for the basal resource. Equilibrium (ii) is stable only if neither the IGprey nor IGpredator subsists on the resource alone. while the IGprey or the IGpredator or both species invade, the equilibrium (ii) will be unstable.

According to the above analysis, the IGprey can invade the state (ii) when $\kappa_{1} u-\alpha \kappa_{3} w /(v+h)-e_{1}>0$, where $u=1$, $w=0$. We can get

$$
\kappa_{1}>e_{1} .
$$

The IGpredator can invade the state (ii) when $\kappa_{2} u+\kappa_{3} v /(v+$ h) $-e_{2}>0$, where $u=1, v=0$. We get

$$
\kappa_{2}>e_{2}
$$

When both inequalities (A.4a) and (A.5a) hold, either consumer can invade the state (ii).

Equilibrium (iii) exists, provides the IGprey can invade at resource density of 1 , that is, inequality (A.4a) holds. The condition for this equilibrium to be unstable with respect to invasion by the IGpredator is $\kappa_{2} u+\kappa_{3} v /(v+h)-e_{2}>0$, where $u=e_{1} / \kappa_{1}, v=\left(1 / \kappa_{1}\right)\left(1-e_{1} / \kappa_{1}\right)$. we can obtain

$$
\frac{\kappa_{2} e_{1}}{\kappa_{1}}+\frac{\kappa_{3}\left(\kappa_{1}-e_{1}\right)}{\kappa_{1}-e_{1}+h \kappa_{1}^{2}}-e_{2}>0 .
$$

In the same way, equilibrium (iv) exists when inequality (A.5a) holds. The condition for this equilibrium to be unstable because of invasion by the IGprey is $\kappa_{1} u-\alpha \kappa_{3} w /(v+$ h) $-e_{1}>0$, where $u=e_{2} / \kappa_{2}, w=\left(1 / \kappa_{2}\right)\left(1-e_{2} / \kappa_{2}\right)$. we can obtain

$$
\frac{\kappa_{1} e_{2}}{\kappa_{2}}-\frac{\alpha \kappa_{3}\left(\kappa_{2}-e_{2}\right)}{\kappa_{2}^{2} h}-e_{1}>0
$$

Finally, equilibrium (v) can exist only if both inequalities (A.6a) and (A.7a) hold. Because of the complication of equilibrium (v), we will not analyze the local stability of this equilibrium. This does not affect our overall research.

\section{Acknowledgment}

The authors would like to thank immensely the reviewers for their very constructive comments and suggestions which have helped us to improve the paper. The project is supported by the NSF of China (no. 11226257; no. 11126187), the Fundamental Research Funds for the Central Universities (no. zyz2011075; no. K50511700002; no. zyz2012084), and the China Postdoctoral Science Foundation (no. 2012M521742).

\section{References}

[1] R. Hengeveld, Dynamics of Biological Invasions, Chapman \& Hall, London, UK, 1989.

[2] A. Hastings, "Models of spatial spread: a synthesis," Biological Conservation, vol. 78, no. 1-2, pp. 143-148, 1996.

[3] N. Shigesada and K. Kawasaki, Biological Invasions: Theory and Practice, Oxford University Press, Oxford, UK, 1997.

[4] J. Frantzen and F. van den Bosch, "Spread of organisms: can travelling and dispersive waves be distinguished?" Basic and Applied Ecology, vol. 1, no. 1, pp. 83-92, 2000.

[5] T. H. Keitt, M. A. Lewis, and R. D. Holt, "Allee effects, invasion pinning, and species' borders," American Naturalist, vol. 157, no. 2, pp. 203-216, 2001.

[6] D. A. Holway, A. V. Suarez, and T. J. Case, "Loss of intraspecific aggression in the success of a widespread invasive social insect," Science, vol. 282, no. 5390, pp. 949-952, 1998.

[7] J. Diamond and T. J. Case, "Overview: introductions, extinctions, exterminations and invasions," in Community Ecology, J. Diamond and T. J. Case, Eds., pp. 65-79, Harper \& Row, San Francisco, Calif, USA, 1986.

[8] J. T. A. Dick, "Post-invasion amphipod communities of Lough Neagh, Northern Ireland: influences of habitat selection and mutual predation," Journal of Animal Ecology, vol. 65, no. 6, pp. 756-767, 1996.

[9] C. MacNeil and J. Prenter, "Differential microdistributions and interspecific interactions in coexisting native and introduced Gammarus spp. (Crustacea: Amphipoda)," Journal of Zoology, vol. 251, no. 3, pp. 377-384, 2000.

[10] T. E. Cottrell and K. V. Yeargan, "Intraguild predation between an introduced lady beetle, Harmonia axyridis (Coleoptera: Coccinellidae), and a native lady beetle, Coleomegilla maculata (Coleoptera: Coccinellidae)," Journal of the Kansas Entomological Society, vol. 71, no. 2, pp. 159-163, 1998.

[11] G. Woodward and A. G. Hildrew, "Invasion of a stream food web by a new top predator," Journal of Animal Ecology, vol. 70, no. 2, pp. 273-288, 2001.

[12] W. E. Snyder, G. M. Clevenger, and S. D. Eigenbrode, "Intraguild predation and successful invasion by introduced ladybird beetles," Oecologia, vol. 140, no. 4, pp. 559-565, 2004.

[13] R. D. Holt and G. A. Polis, "A theoretical framework for intraguild predation," American Naturalist, vol. 149, no. 4, pp. 745764, 1997.

[14] S. D. Mylius, K. Klumpers, A. M. de Roos, and L. Persson, "Impact of intraguild predation and stage structure on simple communities along a productivity gradient," American Naturalist, vol. 158, no. 3, pp. 259-276, 2001.

[15] S. L. Pimm and J. H. Lawton, "On feeding on more than one trophic level," Nature, vol. 275, no. 5680, pp. 542-544, 1978.

[16] S. Diehl and M. Feißel, "Effects of enrichment on three-level food chains with omnivory," American Naturalist, vol. 155, no. 2, pp. 200-218, 2000.

[17] S. Diehl, "The evolution and maintenance of omnivory: dynamic constraints and the role of food quality, Ecology, vol. 84, no. 10, pp. 2557-2567, 2003. 
[18] K. Tanabe and T. Namba, "Omnivory creates chaos in simple food web models,” Ecology, vol. 86, no. 12, pp. 3411-3414, 2005.

[19] M. Arim and P. A. Marquet, "Intraguild predation: a widespread interaction related to species biology," Ecology Letters, vol. 7, no. 7, pp. 557-564, 2004.

[20] E. E. Werner and J. F. Gilliam, "The ontogenetic niche and species interactions in size-structured populations," Annual Review of Ecology and Systematics, vol. 15, pp. 393-425, 1984.

[21] P. Byström, L. Persson, and E. Wahlström, "Competing predators and prey: juvenile bottlenecks in whole-lake experiments," Ecology, vol. 79, no. 6, pp. 2153-2167, 1998.

[22] S. C. Walls and M. C. Williams, "The effect of community composition on persistence of prey with their predators in an assemblage of pond-breeding amphibians," Oecologia, vol. 128, no. 1, pp. 134-141, 2001.

[23] W. H. Day, D. R. Prokrym, D. R. Ellis, and R. J. Chianese, "The known distribution of the predator Propylea quatuordecimpunctata (Coleoptera: Coccinellidae) in the United States, and thoughts on the origin of this species and five other exotic lady beetles in eastern North America," Entomological News, vol. 105, no. 4, pp. 244-256, 1994.

[24] W. L. Tedders and P. W. Schaefer, "Release and establishment of Harmonia axyridis (Coleoptera: Cocchinellidae) in the southeastern United States," Entomological News, vol. 105, no. 4, pp. 228-243, 1994.

[25] A. G. Wheeler Jr. and C. A. Stoops, "Status and spread of the palearctic lady beetles Hippodamia variegata and Propylea quatuordecimpunctata (Coleoptera: Coccinellidae) in Pennsylvania, 1993-1995," Entomological News, vol. 107, no. 5, pp. 291298, 1996.

[26] N. Elliott, R. Kieckhefer, and W. Kauffman, "Effects of an invading coccinellid on native coccinellids in an agricultural landscape," Oecologia, vol. 105, no. 4, pp. 537-544, 1996.

[27] M. W. Brown and S. S. Miller, "Coccinellidae (Coleoptera) in apple orchards of eastern West Virginia and the impact of invasion by Harmonia axyridis," Entomological News, vol. 109, no. 2, pp. 136-142, 1998.

[28] N. Osawa, "Population field studies of the aphidophagous ladybird beetle Harmonia axyridis (Coleoptera: Coccinellidae): life tables and key factor analysis," Researches on Population Ecology, vol. 35, no. 2, pp. 335-348, 1993.

[29] M. L. LaMana and J. C. Miller, "Field observations on harmonia axyridis pallas (Coleoptera: Coccinellidae) in oregon," Biological Control, vol. 6, no. 2, pp. 232-237, 1996.

[30] J. J. Obrycki, K. L. Giles, and A. M. Ormord, "Interactions between an introduced and indigenous coccinellid species at different prey densities," Oecologia, vol. 117, no. 1-2, pp. 279-285, 1998.

[31] Y. Kajita, F. Takano, H. Yasuda, and B. K. Agarwala, "Effects of indigenous ladybird species (Coleoptera: Coccinellidae) on the survival of an exotic species in relation to prey abundance," Applied Entomology and Zoology, vol. 35, no. 4, pp. 473-479, 2000.

[32] J. P. Michaud, "Invasion of the Florida citrus ecosystem by Harmonia axyridis (Coleoptera: Coccinellidae) and asymmetric competition with a native species, Cycloneda sanguinea," Environmental Entomology, vol. 31, no. 5, pp. 827-835, 2002.

[33] H. Yasuda, E. W. Evans, Y. Kajita, K. Urakawa, and T. Takizawa, "Asymmetric larval interactions between introduced and indigenous ladybirds in North America," Oecologia, vol. 141, no. 4, pp. 722-731, 2004.
[34] C. J. Briggs and E. T. Borer, "Why short-term experiments may not allow long-term predictions about intraguild predation," Ecological Applications, vol. 15, no. 4, pp. 1111-1117, 2005.

[35] A. Janssen, M. Montserrat, R. HilleRisLambers, A. M. de Roos, A. Pallini, and M. W. Sabelis, "Intraguild predation usually does not disrupt biological control," in Trophic and Guild Interactions in Biological Control, J. Brodeur and G. Boivin, Eds., pp. 21-44, Springer, Dordrecht, The Netherlands, 2006.

[36] A. Janssen, M. W. Sabelis, S. Magalhães, M. Montserrat, and T. van der Hammen, "Habitat structure affects intraguild predation," Ecology, vol. 88, no. 11, pp. 2713-2719, 2007.

[37] P. Amarasekare, "Trade-offs, temporal variation, and species coexistence in communities with intraguild predation," Ecology, vol. 88, no. 11, pp. 2720-2728, 2007.

[38] P. Amarasekare, "Productivity, dispersal and the coexistence of intraguild predators and prey," Journal of Theoretical Biology, vol. 243, no. 1, pp. 121-133, 2006.

[39] V. H. W. Rudolf, "The interaction of cannibalism and omnivory: consequences for community dynamics," Ecology, vol. 88, no. 11, pp. 2697-2705, 2007.

[40] R. D. Holt and G. R. Huxel, "Alternative prey and the dynamics of intraguild predation: theoretical perspectives," Ecology, vol. 88, no. 11, pp. 2706-2712, 2007.

[41] M. E. Torchin, K. D. Lafferty, A. P. Dobson, V. J. McKenzie, and A. M. Kuris, "Introduced species and their missing parasites," Nature, vol. 421, no. 6923, pp. 628-630, 2003.

[42] R. N. Mack, D. Simberloff, W. M. Lonsdale, H. Evans, M. Clout, and F. A. Bazzaz, "Biotic invasions: causes, epidemiology, global consequences, and control," Ecological Applications, vol. 10, no. 3, pp. 689-710, 2000.

[43] J. T. A. Dick, W. I. Montgomery, and R. W. Elwood, "Intraguild predation may explain an amphipod replacement: evidence from laboratory populations," Journal of Zoology, vol. 249, no. 4, pp. 463-468, 1999.

[44] C. MacNeil, W. I. Montgomery, J. T. A. Dick, and R. W. Elwood, "Factors influencing the distribution of native and introduced Gammarus spp. in Irish river systems," Archiv fur Hydrobiologie, vol. 151, no. 3, pp. 353-368, 2001.

[45] S. J. Mithen and J. H. Lawton, "Food-web models that generate constant predator-prey ratios," Oecologia, vol. 69, no. 4, pp. 542$550,1986$.

[46] R. Law and J. C. Blackford, "Self-assembling food webs: a global viewpoint of coexistence of species in Lotka-Volterra communities," Ecology, vol. 73, no. 2, pp. 567-578, 1992.

[47] J. D. Murray, Mathematical Biology, Springer, Berlin, Germany, 1989.

[48] E. E. Holmes, M. A. Lewis, J. E. Banks, and R. R. Veit, "Partial differential equations in ecology: spatial interactions and population dynamics," Ecology, vol. 75, no. 1, pp. 17-29, 1994.

[49] D. J. Murrell and R. Law, "Heteromyopia and the spatial coexistence of similar competitors," Ecology Letters, vol. 6, no. 1, pp. 48-59, 2003.

[50] A. Morozov, S. Petrovskii, and B.-L. Li, "Spatiotemporal complexity of patchy invasion in a predator-prey system with the Allee effect," Journal of Theoretical Biology, vol. 238, no. 1, pp. 18-35, 2006.

[51] S. V. Petrovskii, A. Y. Morozov, and E. Venturino, "Allee effect makes possible patchy invasion in a predator-prey system," Ecology Letters, vol. 5, no. 3, pp. 345-352, 2002.

[52] S. V. Petrovskii, M. E. Vinogradov, and A. Y. Morozov, "Formation of the patchiness in the plankton horizontal distribution 
due to biological invasion in a two-species model with account for the allee effect," Oceanology, vol. 42, no. 3, pp. 363-372, 2002.

[53] C. S. Elton, The Ecology of Invasions by Animals and Plants, Methuen, London, UK, 1958.

[54] H. A. Mooney and J. A. Drake, Ecology of Biological Invasions of North America and Hawaii, Springer, New York, NY, USA, 1986.

[55] H. G. Baker and G. L. Stebbins, The Genetics of Colonizing Species, Academic Press, New York, NY, USA, 1965.

[56] M. Williamson, "Invasions," Ecography, vol. 22, no. 1, pp. 5-12, 1999.

[57] K. M. Maredia, S. H. Gage, D. A. Landis, and J. M. Scriber, "Habitat use patterns by the seven-spotted lady beetle (Coleoptera: Coccinellidae) in a diverse agricultural landscape," Biological Control, vol. 2, no. 2, pp. 159-165, 1992.

[58] E. W. Evans, "Morphology of invasion: body size patterns associated with establishment of Coccinella septempunctata (Coleoptera: Coccinellidae) in western North America," European Journal of Entomology, vol. 97, no. 4, pp. 469-474, 2000.

[59] E. W. Evans, "Habitat displacement of North American ladybirds by an introduced species," Ecology, vol. 85, no. 3, pp. 637647, 2004.

[60] E. Lucas, I. Gagné, and D. Coderre, "Impact of the arrival of Harmonia axyridis on adults of Coccinella septempunctata and Coleomegilla maculata (Coleoptera: Coccinellidae)," European Journal of Entomology, vol. 99, no. 4, pp. 457-463, 2002.

[61] B. A. Nault and G. G. Kennedy, "Establishment of multicolored Asian lady beetle in Eastern North Carolina: seasonal abundance and crop exploitation within an agricultural landscape," BioControl, vol. 48, no. 4, pp. 363-378, 2003.

[62] Y. Hironori and S. Katsuhiro, "Cannibalism and interspecific predation in two predatory ladybirds in relation to prey abundance in the field," Entomophaga, vol. 42, no. 1-2, pp. 153-163, 1997.

[63] Y. Sakuratani, "New record of Adalia bipunctata (Linnaeus) (Coleoptera, Coccinellidae) from Japan," Japanese Journal of Entomology and Zoology, vol. 62, pp. 627-628, 1994.

[64] Y. Sakuratani, Y. Matsumoto, M. Oka et al., "Life history of Adalia bipunctata (Coleoptera: Coccinellidae) in Japan," European Journal of Entomology, vol. 97, no. 4, pp. 555-558, 2000.

[65] S. V. Petrovskii, H. Malchow, F. M. Hilker, and E. Venturino, "Patterns of patchy spread in deterministic and stochastic models of biological invasion and biological control," Biological Invasions, vol. 7, no. 5, pp. 771-793, 2005.

[66] M. E. Gilpin and M. L. Rosenzweig, "Enriched predator-prey systems: theoretical stability," Science, vol. 177, no. 4052, pp. 902904, 1972. 


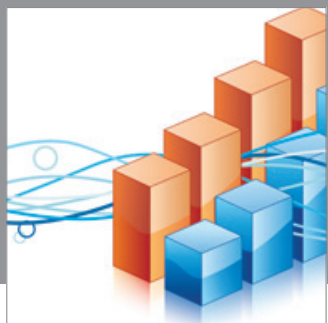

Advances in

Operations Research

mansans

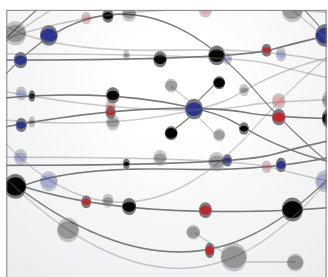

The Scientific World Journal
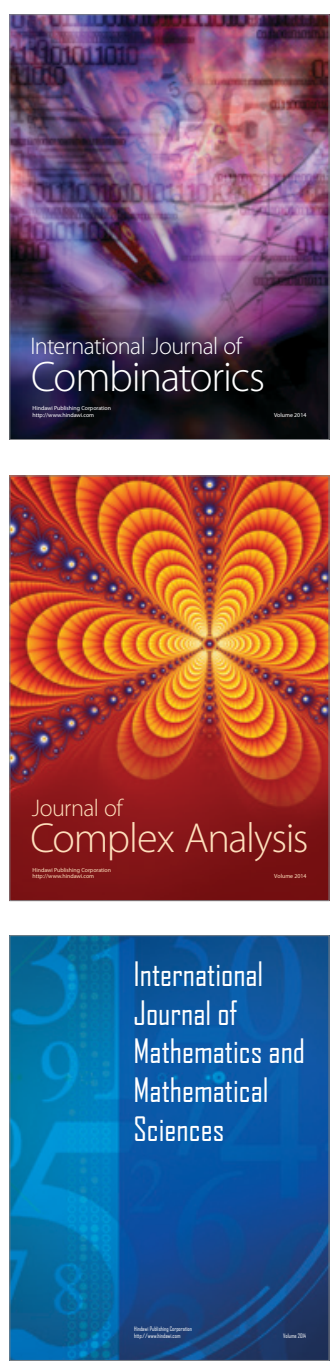
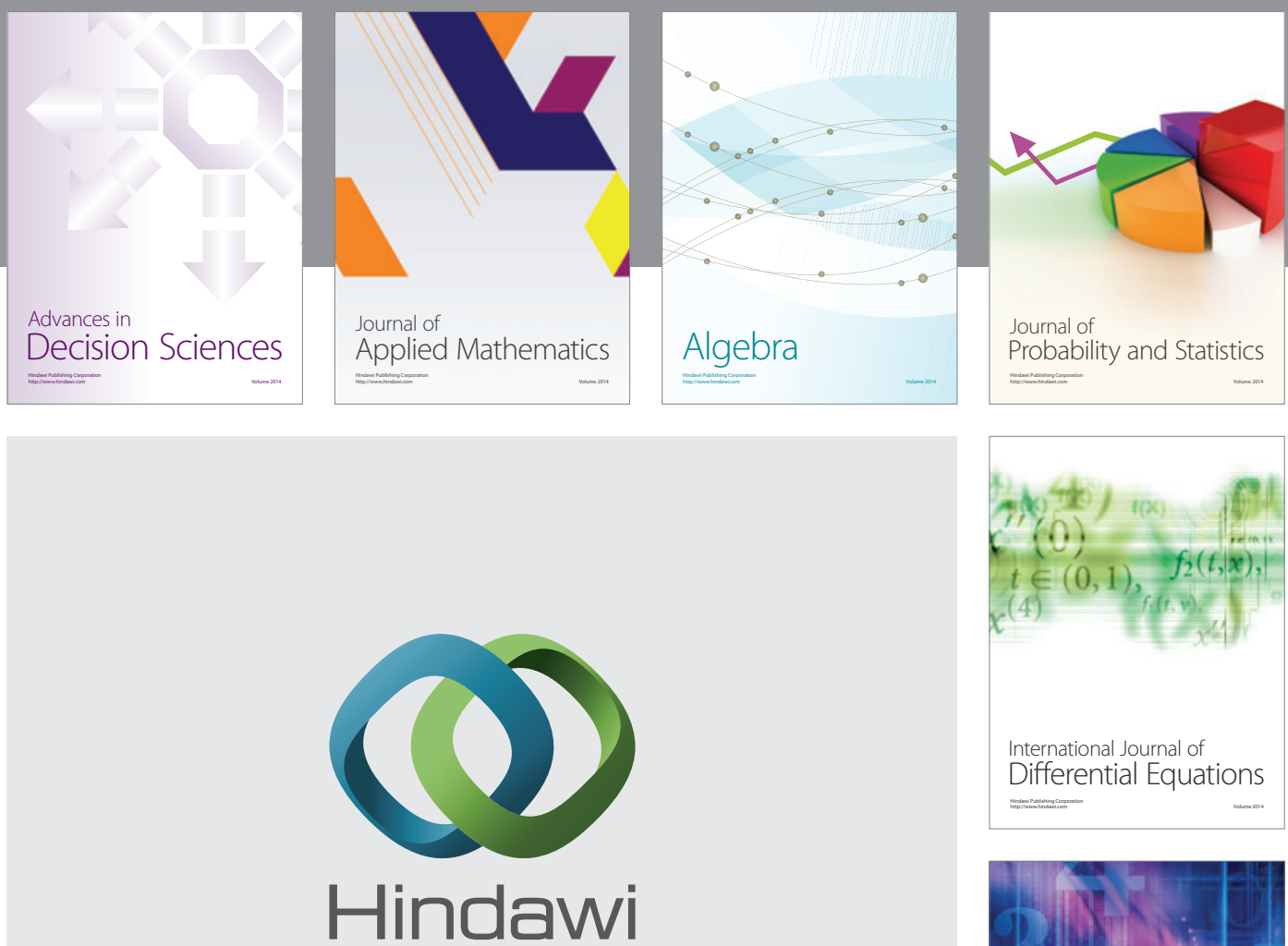

Submit your manuscripts at http://www.hindawi.com
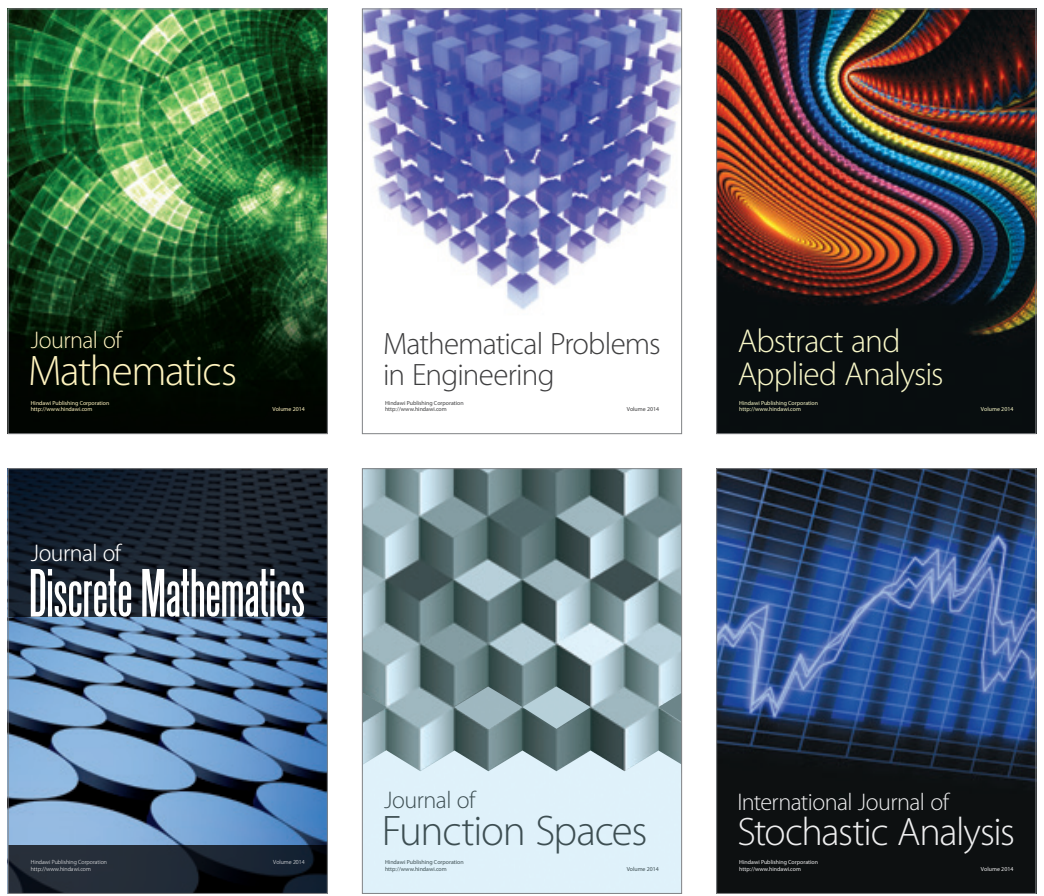

Journal of

Function Spaces

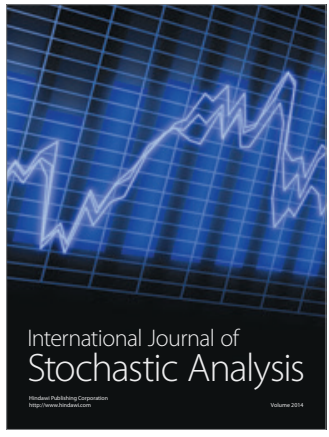

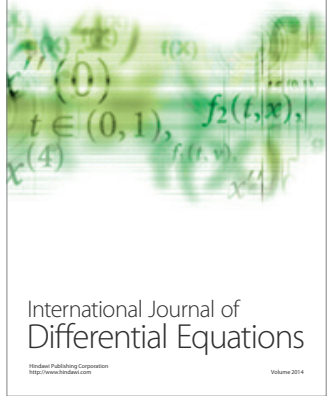
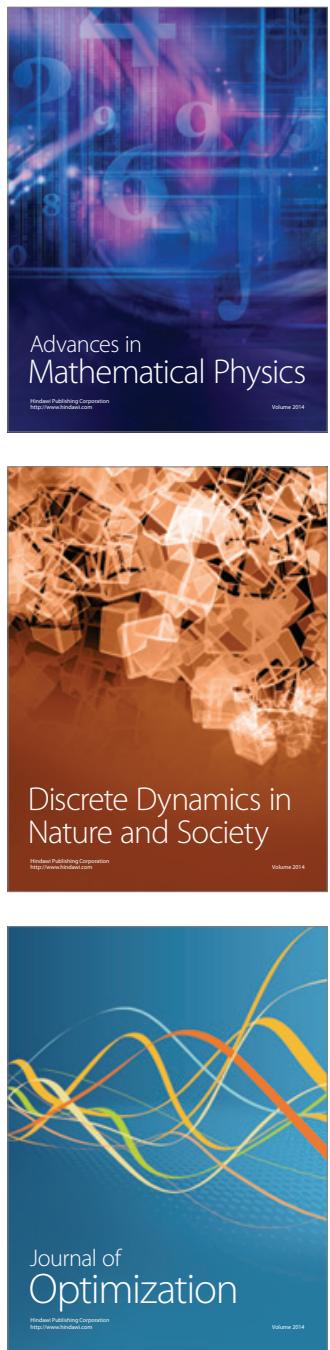